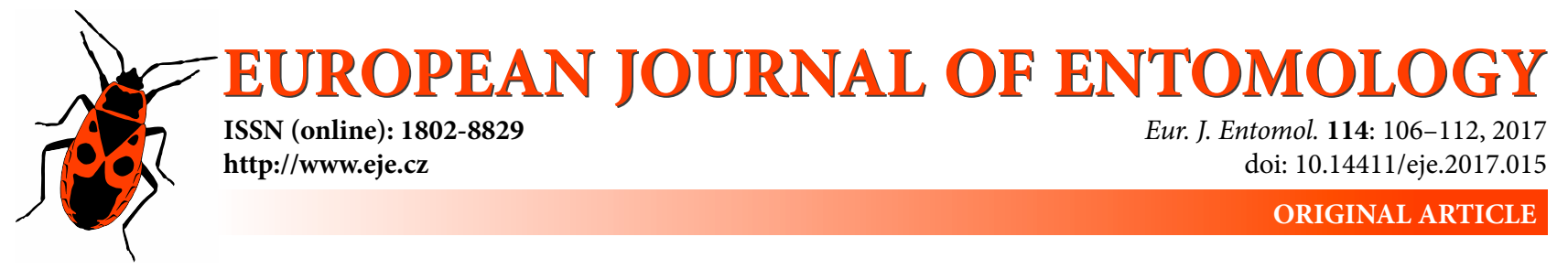

\title{
Effect of ant attendance on aphid population growth and above ground biomass of the aphid's host plant
}

\author{
Afsane HOSSEINI ${ }^{1}$, MoJtaba HOSSEINI ${ }^{1, *}$, Noboru KATAYAMA ${ }^{2}$ and MohSen MEHRPARVAR ${ }^{3}$ \\ ${ }^{1}$ Department of Plant Protection, College of Agriculture, Ferdowsi University of Mashhad, Mashhad, Iran; \\ e-mails: hosseini.af@stu-mail.um.ac.ir,m.hosseini@um.ac.ir \\ ${ }^{2}$ Kyoto University, Kyoto Center for Ecological Research, Japan; e-mail: noborukata1913@gmail.com \\ ${ }^{3}$ Department of Biodiversity, Institute of Science and High Technology and Environmental Sciences, Graduate University \\ of Advanced Technology, 7631133131 Kerman, Iran; e-mail: mehrparvar@aphidology.com
}

Key words. Hemiptera, Aphididae, Hymenoptera, Formicidae, ant-aphid interaction, aphid performance, population growth, developmental stage, plant yield

\begin{abstract}
Ant-aphid mutualism is considered to be a beneficial association for the individuals concerned. The population and fitness of aphids affected by ant attendance and the outcome of this relationship affects the host plant of the aphid. The main hypothesis of the current study is that ant tending decreases aphid developmental time and/or increases reproduction per capita, which seriously reduces host plant fitness. The effect of attendance by the ant Tapinoma erraticum (Latreille, 1798) (Hymenoptera: Formicidae) on population growth and duration of different developmental stages of Aphis gossypii Glover (Hemiptera: Aphididae) were determined along with the consequences for the fitness of the host plant of the aphid, Vicia faba L., in greenhouse conditions. The initial aphid density was manipulated in order to study aphid performance due to density-dependent changes in ant attendance. The population growth rate of ant attended aphids was more than that of unattended aphids. However, the ratio of $1^{\text {st }}-2^{\text {nd }}$ nymphs to adults in aphid populations attended by ants was lower. The yields of bean plants on which the aphids were attended by ants were significantly greater than those of unattended plants. This study indicates that ants not only increase aphid fitness in terms of their population growth rate, but also benefit the host plant.
\end{abstract}

\section{INTRODUCTION}

Mutualism is a reciprocal relationship in which all participants benefit from the interaction (i.e., the profits exceed the costs) (Fischer et al., 2002; Yoo \& Holway, 2011; Yao, 2014). The cost to benefit ratio in mutualism changes with the intrinsic features of both partners (e.g. the initial number of partners at the commencement of a relationship) and biotic/abiotic environmental factors (Stadler \& Dixon, 1998; Styrsky \& Eubanks, 2010; Yoo \& Holway, 2011; Barton \& Ives, 2014; Singh et al., 2016). Thus, mutualism has a context-dependent aspect, that is, the net benefits for a given species depend on ecological conditions (Zhang et al., 2015).

The ant-aphid interaction is a common mutualism in which ants provide aphids several beneficial services, such as protection by removing the aphid's natural enemies (Bronstein \& Barbosa, 2002; Stadler \& Dixon, 2005) and reduce the incidence of disease by removing aphid waste products (i.e., honeydew) (Way, 1954; Yao et al., 2000) in return for aphid honeydew. Consequently, ant attendance can result in an increase in the abundance of the aphid and/ or in its per capita fitness (El-Ziady \& Kennedy, 1956; Bristow, 1984; Flatt \& Weisser, 2000; Cooper et al., 2007; Yoo \& Holway, 2011). Increases in the abundance and survivorship of aphids due to ant tending are reported by many authors (e.g. Flatt \& Weisser, 2000; Renault et al., 2005; Tokunaga \& Suzuki, 2008).

From a general perspective on the nature of condition dependency in mutualism, ant attendance not only has positive effects (e.g. Breton \& Addicott, 1992; Morales, 2000), but also negative effects on the per capita fitness of aphids. Indeed, a reduction in body size and number of embryos in aphids (Stadler \& Dixon, 1998; Yao, 2014) and predation upon aphids by ants (Pontin, 1958; Billick et al., 2007) are reported costs associated with ant attendance. Given that ant attendance can also influence the developmental time of aphid nymphs (Stadler \& Dixon, 1998; Yao et al., 2000), examining its effect on aphids in each developmental stage can provide a critical insight into understanding the fitness outcome and population dynamics of aphids (Cushman

\footnotetext{
* Corresponding author; e-mail: m.hosseini@um.ac.ir.
} 
et al., 1994). Although there is a substantial body of literature on the developmental time of aphids in life tables for ant attended and unattended aphids (Stadler \& Dixon, 1998; Flatt \& Weisser, 2000; Yoo \& Holway, 2011), little is known about how ant attendance changes the age-structure of aphid populations. The primary objective of the present study is to determine how the population growth of the aphid, Aphis gossypii Scopoli, is affected by the attendance of the ant, Tapinoma erraticum (Latreille, 1798) and how this is linked to changes in the age structure of the aphid population.

Since ant attendance might influence the developmental time of individual aphids and even the population dynamics of aphids, it is necessary to determine how ant attendance changes during the course of aphid population growth. Therefore, the present study's second objective is to determine how the level of ant attendance is affected by the size of an aphid colony.

As ant attendance may result in an increase in aphid population size and aphid nymphs and adults ingest very large amounts of phloem sap, which can result in severe carbon and/or drought stress in the host plant (van Emden \& Harrington, 2007), the outcome of an ant aphid interaction can subsequently affect the growth or biomass of the aphid's host plant. Hence, the third objective of this study is to address whether ant attendance affects the growth (in this case, the above-ground plant biomass) of the host plant, Vicia faba L. of the aphid by its effect on aphid colony size.

\section{MATERIALS AND METHODS}

\section{Plant, aphid and ant}

Vicia faba L. (Fabaceae, cv. Barkat) was used as the host plant of the aphid, A. gossypii, in this study. Vicia faba has extrafloral nectaries at the base of each leaf (EFNs), which are known to be attractive to ants (Katayama et al., 2014). The plants were individually grown from seed in 7-L polyethylene pots $(23 \mathrm{~cm}$ in diameter $\times 17 \mathrm{~cm}$ in height) filled with a mixture of sand and clay $(2: 1)$. The pots were enclosed in transparent cylindrical finemesh cages $(50 \mathrm{~cm}$ height $\times 30 \mathrm{~cm}$ diameter $)$ and kept in a research greenhouse at the College of Agriculture of Ferdowsi University of Mashhad, Mashhad, in northeastern Iran. An average temperature and relative humidity $(\mathrm{RH})$ were programmed at 26 $\pm 1^{\circ} \mathrm{C}($ mean $\pm \mathrm{SD})$ and $65 \pm 5 \% \mathrm{RH}$. The pots were watered daily with tap water for two weeks. After two weeks, the seedlings used in the assays described below were up to $20 \mathrm{~cm}$ in height and had 8-10 extrafloral nectaries (EFNs). In a preliminary survey of a bean field located at the Agricultural Research Station of Ferdowsi University of Mashhad, Iran $\left(36^{\circ} 15^{\prime} \mathrm{N}, 5^{\circ} 28^{\prime} \mathrm{E}\right)$, when the plants had 4 to 6 leaves, the number of Aphis gossypii Glover (Hemiptera: Aphididae) in the early colonies forming on $V$. faba, was approximately 12 individuals in various stages of development. Therefore, based on this the average (12 individuals) initial number of aphids, and one upper (24 individuals) and one lower level ( 3 individuals) aphid number were chosen as the experimental treatments. In order to achieve a stable age distribution and exponential population growth from the commencement of the experiment (Vehrs et al., 1992; Hosseini et al., 2010), aphids of various ages (first or second instar + third or fourth instar + adult) were transferred.

A colony of cotton aphids, A. gossypii, originally obtained from $V$. faba, was reared on $V$. faba under the same greenhouse condition as previously described for at least 4 generations before being used in this study. To prevent ants from accessing the aphid colonies, each of the potted plants infested with an aphid colony was placed in a tray filled with water.

Colonies of the erratic ant, Tapinoma erraticum (Latreille, 1798) (Hymenoptera: Formicidae), which is common in agricultural land in Mashhad and its surrounding area, were collected from several sites on the campus of Ferdowsi University of Mashhad, Mashhad, Khorasan-e-Razavi. The area from which they were collected is an open area with a dry climate and relatively fertile soil covered by herbaceous plants. This species is mainly reported to be from Iran's northeastern region, specifically the city of Mashhad (Hosseini et al., 2015).

Fifty ant colonies, consisting of one queen and approximately 500 workers and a brood of 50, were prepared for this study. Each ant colony was kept in a Vaseline-lined polyethylene container, which was half-filled with natural soil from an ant's nest. The container was placed in a tray filled with water to prevent the ants from escaping. It was partially covered with a dark piece of cardboard to maintain a dark environment, thus mimicking that of a natural nest (henceforth, the container is referred to as an "ant nest"). The ant nests were placed in a greenhouse and exposed to natural light condition. Before starting the experiments, the ant colonies were fed for two weeks on a sugar solution (10 $\%$ )-filled glass tube ( $9 \mathrm{~cm}$ in height $\times 1.5 \mathrm{~cm}$ in diameter), which was loosely capped with cotton so as to allow the ants free access to the sugar solution. Water was sprayed twice a day onto the surface of the soil in the ant nests to keep them moist.

\section{Aphid population dynamics and age structure}

To determine the effect of different initial aphid numbers on the intensity of the ant-aphid relationship and its effect on the above-ground biomass produced by the bean plants, a microcosm experiment was carried out in a greenhouse from September 3rd to October $25^{\text {th }}, 2013$. The experiment was of a completely randomized design $(3 \times 2$ full factorial $)$ with three initial aphid numbers (3, 12 and 24 aphids) with either ants present $(A P)$ or not present $($ non- $A P)$. In this experiment, to determine how attendance by ants altered the developmental time of the different aphid stages and their reproduction, aphid developmental stages were recorded (see below). Each treatment combination was replicated 5 times. Hence, 30 plants (at the 8-10 leaf stage) were used in this experiment. The plants were then placed inside of a rectangularshaped enclosure made of wood and covered with a gauze net $\left(110 \times 70 \times 90 \mathrm{~cm}^{3}\right)$.

Aphids were transferred with the aid of a camel hair brush onto the underside of the plant's upper leaves. Eight hours after the aphids were transferred, ant nests were individually placed in the enclosure at a distance of $20 \mathrm{~cm}$ from the plants in the $A P$ treatment. The ants were able to access plants via a paper bridge (1 $\mathrm{cm}$ wide and $30 \mathrm{~cm}$ long) between the rim of the plant pot and the ant nest. To prevent ants from escaping, the pot rim was smeared with Vaseline. After around $20 \mathrm{~min}$, the ants climbed the plant and searched for food. It took about $60 \mathrm{~min}$ for the worker ants to discover and start to visit the EFNs or tend the aphids on plants. Thereafter, the numbers of ants visiting a plant and aphids at each developmental stage were counted every three days for one month. In this experiment, the developmental stages were categorized as either: $1^{\text {st }}-2^{\text {nd }}$ instar, $3^{\text {rd }}-4^{\text {th }}$ instar or adult. The number of ants visiting the plant was counted for $10 \mathrm{~s}$, with 3 replications over a period of $10 \mathrm{~min}$, as described by Fischer et al. (2005). All these results were recorded between 9:00-11:00 a.m. After 30 days, the above-ground parts of the plants were harvested and lightly washed with distilled water and then oven-dried for 48 $\mathrm{h}$ at $70^{\circ} \mathrm{C}$. The plant dry mass was weighed using a digital bal- 
ance (Sartorius GD503, Germany, sensitivity: $1 \mathrm{mg}$ ) and used as a measure of plant biomass.

\section{Data analysis}

The 30-day microcosm experiment, which included 10 census records, was divided into three 10-day intervals as follows: the first (start of ant attendance), the second (peak ant attendance), and the third time (ant attendance declining). Hence, there was on average three censuses in each time interval. To determine the effect of the initial number of aphids and ant presence (or absence) on aphid abundance during these three intervals, a $3 \times 2$ factorial design in a repeated measures two-way ANOVA was used. If the interaction between intervals and initial aphid numbers, and between intervals and ant presence (or absence), were significant ( $\mathrm{P}$ $<0.05$ ), a Tukey test was used (Howell, 2002).

To determine the effect of initial numbers of aphids on the level of ant tending in terms of the number of ants attending each aphid colony on each plant in the three time intervals, the ant to aphid colony ratio was subjected to a repeated measures one-way ANOVA (Wilk's-Lambda) (Scheiner, 2001).

To assess whether the aphid population growth rate was influenced by ant attendance and the initial number of aphids, the aphid's $r$ was estimated using the following formula (Chau et al., 2005; Hosseini et al., 2010):

$r=\frac{\ln \left(N_{x+t} / N_{x}\right)}{t}$

where, $N_{x}$ is the population density at time $x, N_{x+\mathrm{t}}$ the population density at time $x+\mathrm{t}$ and $t$ the difference in days between time $x$ $+\mathrm{t}$ and $x$.

To evaluate the main and interactive effects of aphid initial number and ant presence (or absence) on the numbers of aphids in the different developmental stages $\left(1^{\text {st }}-2^{\text {nd }}\right.$ instar, $3^{\text {rd }}-4^{\text {th }}$ instar and adult) at the end of the experiment, a repeated measures twoway MANOVA (Wilk's-Lambda) was used. For each significant MANOVA ( $\mathrm{P}<0.05)$, a t-test was (Proc t-test) used to assess the potential contribution of each variable to the significant difference in the overall multivariate interactive effect of ant presence (or absence) and time intervals. To determine the reproduction of each adult aphid in the population during the three time intervals, the numbers of $1^{\text {st }}-2^{\text {nd }}$ nymph to adult aphid ratio was calculated.

The effect of initial aphid numbers and ant attendance on above-ground plant dry mass was evaluated using a two-way ANOVA. Accordingly, if significant differences between the means of plant dry mass were detected, Fisher's Protected LSD test was performed.

Regression analyses were also used to determine how initial aphid numbers affected the population growth rate of $A$. gossypii and the associated plant biomass of bean plants attended and not attended by ants.

Before ANOVA analyses, normality and homogeneity of variance were determined using Kolmogrov-Smirnov and Bartlett tests, respectively. SAS software, version 9.2 was used for all statistical analyses (SAS Institute, 2008).

\section{RESULTS}

An analysis of repeated measures ANOVA revealed that the mean aphid abundances recorded in the microcosm experiment were significantly affected by the interaction between time interval and aphid initial numbers as well as the interaction between time interval and ant presence (or absence) (Table 1, Figs 1-2). Regardless of ant presence (or absence), the mean aphid abundance increased over time.

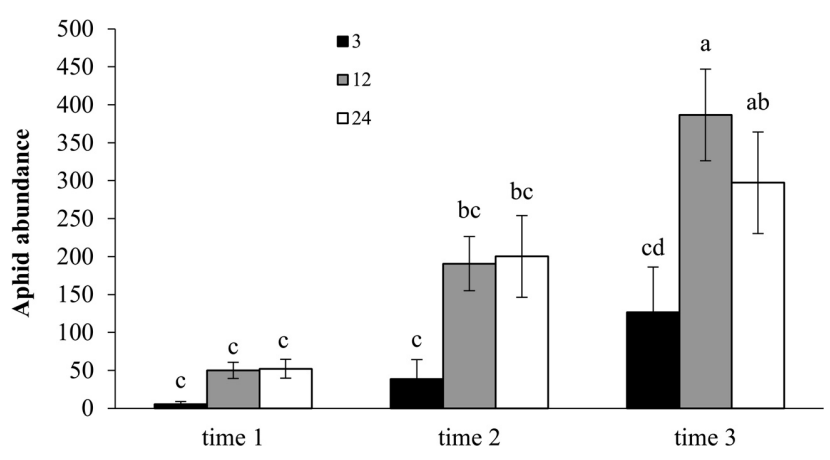

Fig. 1. Effect on the abundance of Aphis gossypii of the initial numbers of aphids $(3,12$ and 24 individuals per plant) and the time after the beginning of the experiment $(0-10,10-20$ and $20-30 \mathrm{~d}$ ). Different letters denote significant difference between treatments $(P<0.05)$. Bars show SE values.

In the third time interval, the mean aphid abundance resulting from an initial number of 12 aphids was the highest recorded. In the three time intervals, regardless of initial aphid numbers, aphids were more abundant on AP plants. However, the three-way interaction between time interval, initial aphid numbers and ant presence (or absence) did not have a significant effect on the mean aphid abundance (Table 1).

The mean number of ants visiting an aphid colony on a plant was significantly affected by the initial number of aphids and time interval, and their interactive effect (repeated measures ANOVA: time intervals: Wilks' lambda = $0.318, F_{2,13}=13.91, P=0.001$; aphid density: $F_{1,13}=11.55$, $P=0.004$; their interaction: Wilks' lambda $=0.537, F_{2,13}$ $=5.6, P=0.01)$. The highest numbers of ants attending aphids was recorded in all 3 different initial numbers of aphid treatments in the first time interval. Over time, the level of ant tending in each treatment decreased and the least tending was recorded in the treatment initiated with 24 aphids (Fig. 3).

The aphid population growth rate during the first and last time intervals was significantly affected by the interaction between initial aphid number and ant presence (or absence) (two-way ANOVA: interaction between ant presence (or absence) and aphid density: $F_{2,24}=17.47, P=0.001$ ). The highest aphid $r$ recorded in the first and third time intervals was recorded in those initiated with 3 aphids in the $A P$ treatment. Except for the initial number of 3 aphids in the non- $A P$ treatment (none survived in this treatment), the

Table 1. Repeated measures two-way ANOVA of the results of the experiment to determine the effect of the initial aphid numbers, ant presence (or absence) and time interval (0-10, 10-20 and 20-30 d after the beginning of the experiment) on the abundance of Aphis gossypii.

\begin{tabular}{lccc}
\hline Source of variation & $\mathrm{df}$ & F-value & $\mathrm{P}$ \\
\hline Initial aphid number (Density) & 2 & 9.55 & 0.001 \\
Ant presence (Ant) & 1 & 23.38 & 0.001 \\
Time interval (Time) & 2,23 & 67.52 & 0.001 \\
Density $\times$ Ant & 2 & 0.32 & 0.732 \\
Time $\times$ Density & 4,46 & 5.22 & 0.001 \\
Time $\times$ Ant & 2,23 & 24.68 & 0.001 \\
Time $\times$ Density $\times$ Ant & 4,46 & 0.35 & 0.849 \\
\hline
\end{tabular}




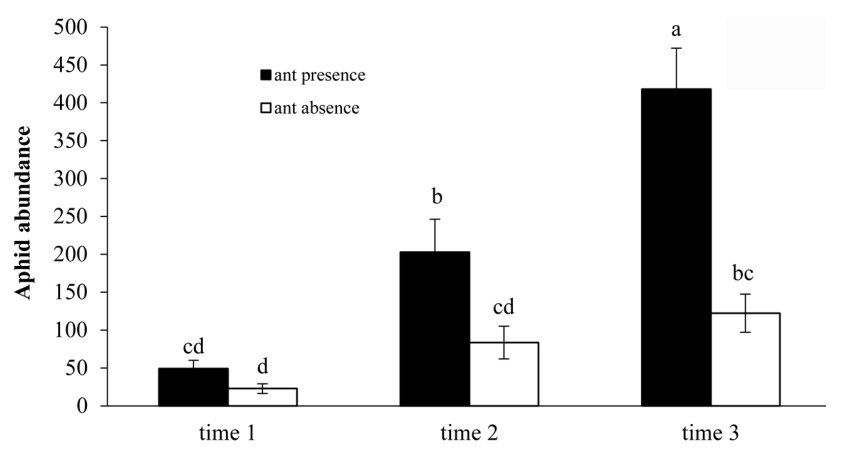

Fig. 2. The abundance of Aphis gossypii in colonies attended and not attended by ants at 0-10, 10-20 and 20-30 days after the beginning of the experiment. Different letters denote a significant difference between treatments $(P<0.05)$. Bars show SE values.

lowest aphid $r$ was recorded in the initial number of 24 aphids in the non-AP treatment (Fig. 4).

There are significant differences in the number of aphids in each developmental stage associated with the main effects [i.e., ant presence (or absence), initial aphid numbers and time interval] and the interactive effect of ant tending and time interval (Table 2). There were significantly more $1^{\text {st }}$-2nd instars nymphs in ant attended than unattended colonies over time (t-test: time $1: t_{8}=3.58, P=0.07$; time $\left.2: t_{8}=3.192, P=0.01 ; t_{8}=5.45, P=0.001\right)$, which indicates that ant attendance resulted in an increase in aphid reproduction. Consequently, as shown in Fig. 2, the population growth rate of ant attended colonies was significantly greater than that of unattended aphid colonies. However, during the first two time intervals, the ratio of $1^{\text {st }}-2^{\text {nd }}$ nymphs to adult aphids in ant attended colonies was lower than that in unattended colonies. In the third time interval, the ratio of $1^{\text {st }-2^{\text {nd }}}$ nymphs to adult aphids in ant attended colonies was equal to that in unattended colonies (Table 3 ).

At the end of this experiment, the above-ground plant biomass recorded was significantly affected by the interaction between initial aphid numbers and ant presence (or absence) (two-way ANOVA: $F_{5,24}=5.24, P=0.003$ ). The greatest plant biomass was recorded in the $A P$ treatment initiated with 24 aphids and the smallest in the non- $A P$ treatment initiated with 12 aphids (Fig. 5). In the absence of

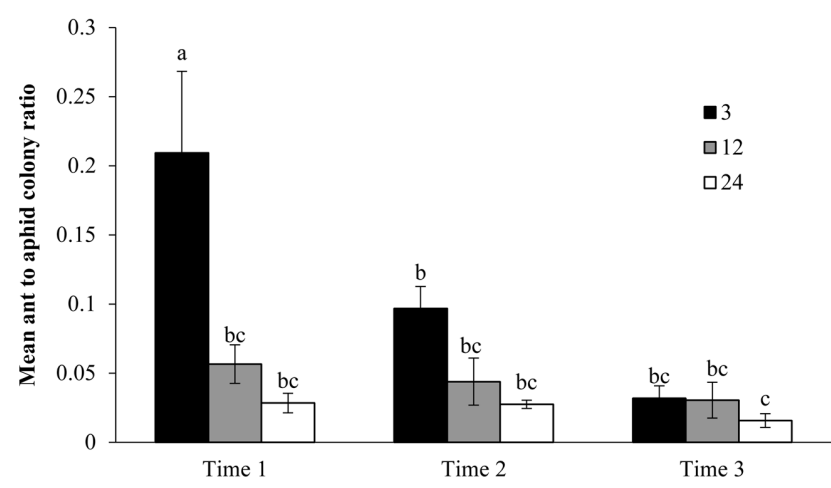

Fig. 3. Mean ant to aphid colony ratio ( \pm SE) recorded over 10 days attending aphid colonies that initially contained 3, 12 or 24 aphids, recorded at different times from the start of the experiment. Different letters denote a significant difference between treatments $(P<0.05)$. Bars show SE values.

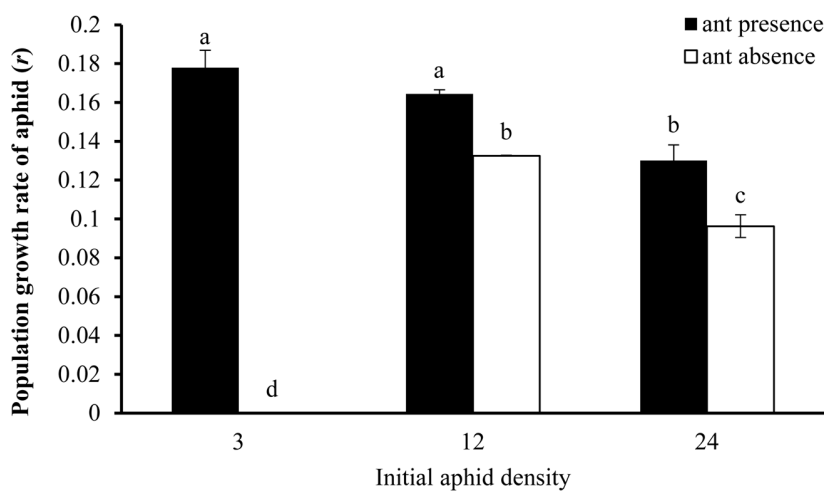

Fig. 4. The mean population growth rate of Aphis gossypii in colonies started with different numbers of aphids that were either attended or not attended by ants recorded in the first and third time intervals after the start of the experiment. Different letters denote a significant difference between treatments $(P<0.05)$. Bars show SE values.

ants, the plant biomass markedly decreased with increase in mean aphid abundance $\left(Y=-0.027 X+0.470, R^{2}=0.63\right.$, $P=0.001)$. In contrast, in the presence of ants, the plant biomass increased with increase in the aphid abundance $(Y$ $\left.=0.042 X+0.466, R^{2}=0.61, P=0.02\right)$.

\section{DISCUSSION}

The results of this study indicate that, irrespective of the differences in the initial numbers of aphids, the population growth rate of ant attended aphids $(0.157)$ was greater than that of unattended aphids (0.076) (Fig. 4). This is due to the fact that the ratio of $1^{\text {st }}-2^{\text {nd }}$ instar nymphs to adult aphids in $A P$ treatments was smaller than that recorded in non- $A P$ treatments (Table 3 ). More interestingly, bean plant biomass was significantly higher in $A P$ (ant-presence) than in non- $A P$ (ant absence) treatments (Fig. 5).

The Aphis gossypii colonies on $A P$ plants were larger than those on non- $A P$ plants at all three time intervals (Fig. $2)$. In addition, the population growth rate $(r)$ of ant attended aphid colonies was higher than that of unattended ones (Fig. 4). Many studies report that the ant-aphid mutualistic relationship results in an increase in the reproduction and life span of the aphids and larger aphid populations (Stadler \& Dixon, 1999; Renault et al., 2005; Powel \& Silverman, 2010).

The highest aphid population increases were recorded for colonies started with 3 aphids in the $A P$ treatment. Similar

Table 2. Repeated measures two-way MANOVA (Wilk's-Lambda) of the results of the experiment to determine the effect of the initial aphid number, ant presence (or absence) and time interval (0-10, 10-20 and 20-30 d after the beginning of the experiment) on the numbers of $1^{\text {st }}-2^{\text {nd }}, 3^{\text {rd }}-4^{\text {th }}$ instar nymphs and adults of Aphis gossypii.

\begin{tabular}{lccc}
\hline Source of variation & Wilk's lambda & $\mathrm{F}$ & $\mathrm{P}$ \\
\hline Initial aphid number (Density) & 0.482 & 2.34 & 0.05 \\
Ant presence (Ant) & 0.586 & 3.772 & 0.03 \\
Time interval (Time) & 0.244 & 11.618 & 0.001 \\
Density $\times$ Ant & 0.832 & 0.513 & 0.79 \\
Time $\times$ Density & 0.590 & 1.659 & 0.09 \\
Time $\times$ Ant & 0.518 & 4.413 & 0.01 \\
Time $\times$ Density $\times$ Ant & 0.833 & 0.537 & 0.88 \\
\hline
\end{tabular}




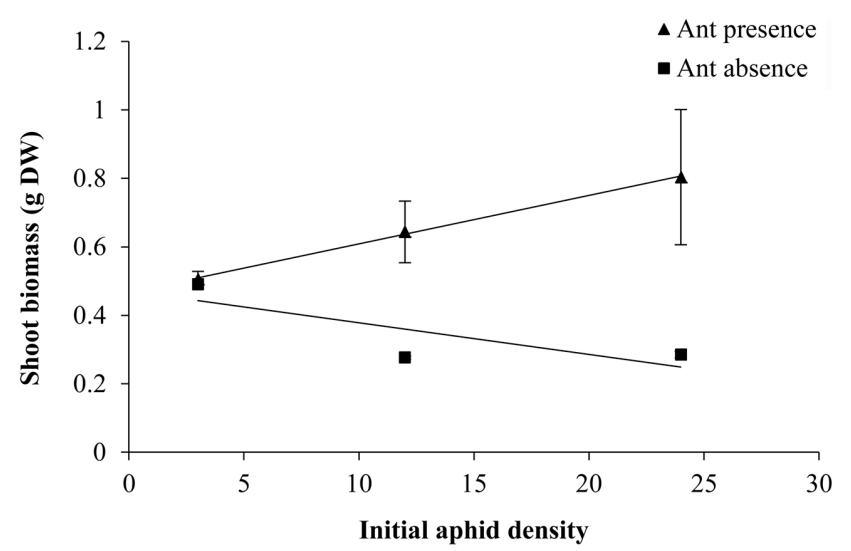

Fig. 5. Mean above-ground biomass of bean plants infested with different initial numbers of aphids and either attended or not attended by ants. Lines indicate linear regressions for the $A P$ and non- $A P$ treatments, respectively $(A P: Y=0.042 X+0.466$, non- $A P$ : $Y=-0.027 X+0.470)$. Bars show SE values.

to the results of the current study, the per capita growth rate of Aphis varians in small colonies is significantly greater than in large colonies (Breton \& Addicott, 1992). Indeed, in the present study, none of the aphid colonies started with 3 aphids in the non-AP treatment survived (Fig. 4). Small colonies easily become extinct given that solitary aphids are usually more vulnerable to plant defense than are aggregated aphids. The latter, however, can sometimes profit from colonies overcoming the host plants' defense and improving sap quality (Prado \& Tjallingii, 1997; Price et al., 2011). In contrast to the vulnerability of non-ant attended aphids living in small colonies, the survival and growth of $A P$ aphids in small colonies are dramatically improved by the presence of ants (Fig. 4), probably due to the high level of ant attendance per aphid (Fig. 3). Negative density-dependent interaction between ant recruitment and the size of aphid aggregations (Breton \& Addicott, 1992; Sakata, 1995; Morales, 2000; Yoo \& Holway, 2011) resulted in the aphids in small aphid colonies (initiated with 3 aphids) individually being tended by more ants.

An abundance of $1^{\text {st }-2^{\text {nd }}}$ instar aphids enhance ant attendance. In spite of this, ant attendance decreased the ratio of $1^{\text {st }}-2^{\text {nd }}$ instar nymphs to adult aphids during the first two time intervals (Table 3 ). Because reproduction per adult in $A P$ aphid colonies was higher than that in non- $A P$ colonies (Fig. 5), the reduction in the ratio of $1^{\text {st }}-2^{\text {nd }}$ instar nymphs to adults in ant attended colonies indicates that ant attendance most probably resulted in a greater increase in the rate of nymphal developmental than in the rate of reproduction. These findings suggest that tending ants promote the population growth of aphids by altering the age structure of a colony. Given that the ants prefer mature aphids because they excrete a larger amount of honeydew than young aphids (Fischer et al., 2002). This modification of aphid age-structure by ants can facilitate the ant-aphid mutualism. To support this view, Flatt \& Weisser (2000) report that an ant attended cotton aphid colony matured earlier than an unattended one. In the presence of ants, a more rapid development of the immature stages is also reported for Aphis fabae (El-Ziady \& Kennedy, 1956; El-Ziady, 1960), a lycaenid butterfly (Jalmenus evagoras) (Pierce et al., 1987) and Publilia reticulata (Hemiptera: Membracidae) (Bristow, 1984).

The current study hypothesized that increasing the colony size of aphids, via a mutualistic relationship with ants, would have a negative effect on plant performance. Contrary, to expectations, the present study's results indicate that the ant-aphid mutualism significantly enhances the total above ground biomass of the bean plant compared to that recorded for aphid-infested plants without ants. Therefore, a positive effect of ants tending aphids on plants is a greater production of above ground plant biomass. For example, by removing honeydew, ants mitigate the negative effects of the aphid honeydew droplets remaining on host plant leaves (Flatt \& Weisser, 2000). Moreover, the activity of ants underground evidently affects the physical, chemical, and microbiological state of soil. By tunneling in the soil, ants make a major contribution to the aeration of soil (Dean et al., 1997). In the present study, less than $24 \mathrm{~h}$ after placing an ant nest container close to a pot, the workers transferred all their larvae into the soil in the pot, which was followed by all of the ant colony moving into the pot. In addition to the effect on the physical properties of soil, earlier studies reveal that soil with an ant nest contains more mineral nitrogen, carbon, and potassium than soil without nests (Dean \& Yeaton, 1993; Dauber et al., 2001). Sources of soil nutrients may be the honeydew excreted by aphids and the dead bodies and exuvia of aphids that ants transport to their nest (Banks, 1962). The accumulation of organic matter in soil contained in ant's nest provides an environment that is favourable for decomposing microorganisms and the activity of microbes in the soil in general (Dauber \& Wolters, 2000). Therefore, ant activity positively influences the nutritional state of the flora and fauna in soil, which can result in better soil conditions for the growth and development of plants.

In the present study, the ant $T$. erraticum not only improved the performance of $A$. gossypii colonies in terms of the population growth rates of all the different sized aphid colonies (El-Ziady \& Kennedy, 1956; Flatt \& Weisser, 2000; Powel \& Silverman, 2010; Styrsky \& Eubanks, 2010), but also benefited the aphid's host plant (Hansen et al., 2006). The positive consequences of the ant-aphid

Table 3. Abundance of $1^{\text {st }}-2^{\text {nd }}$ instar nymphs, adults and the ratio of $1^{\text {st }}-2^{\text {nd }}$ instar nymphs to adults of Aphis gossypii in colonies attended and not attended by ants in the three time intervals $(0-10,10-20$ and 20-30 d after the beginning of the experiment).

\begin{tabular}{|c|c|c|c|c|c|c|c|c|c|}
\hline \multirow{2}{*}{ Ant } & \multicolumn{3}{|c|}{ Time 1} & \multicolumn{3}{|c|}{ Time 2} & \multicolumn{3}{|c|}{ Time 3} \\
\hline & 1-2 nymph & Adult & 1-2 / Adult & 1-2 nymph & Adult & 1-2 / Adult & 1-2 nymph & Adult & 1-2 / Adult \\
\hline Presence & 31.65 & 11.25 & 2.81 & 122.86 & 38.81 & 3.16 & 276.33 & 122.88 & 2.24 \\
\hline Absence & 12.13 & 2.92 & 4.18 & 48.56 & 12.16 & 3.99 & 66.86 & 32.7 & 2.04 \\
\hline
\end{tabular}


system for the host plant, in the absence of aphid natural enemies and alternative herbivores, probably indicates that ants (as the active partners in the mutualism) can affect the fitness of the aphid's host plant as long as the requirements of the colony are satisfied. Thus, the ant-aphid relationship can enhance the dynamics of ecological communities.

ACKNOWLEDGEMENTS. We are grateful to I. Hodek and anonymous reviewers for constructive comments. We also thank the research deputy of the Ferdowsi University of Mashhad for financially supporting this research.

\section{REFERENCES}

BANKS C.J. 1962: Effects of the ant Lasius niger (L.) on insects preying on small populations of Aphis fabae Scop. on bean plants. - Ann. Appl. Biol. 50: 669-679.

BARTON B.T. \& IVES A.R. 2014: Direct and indirect effects of warming on aphids, their predators, and ant mutualists. Ecology 95: 1479-1484.

Billick I., Hammer S., Reithel J.S. \& Aвbot P. 2007: Ant-aphid interactions: are ants friends, enemies, or both? - Ann. Entomol. Soc. Am. 100: 887-892.

Breton L.M. \& Addicott J.F. 1992: Density-dependent mutualism in an aphid-ant interaction. - Ecology 6: 2175-2180.

Bristow C.M. 1984: Differential benefits from ant-attendance to two species of Homoptera on New York ironweed. - J. Anim. Ecol. 53: 715-726.

Bronstein J.L. \& Barbosa P. 2002: Multitrophic/multispecies mutualistic interactions: the role of non-mutualists in shaping and mediating mutualisms. In Hawkins B. \& Tsharntke T. (eds): Multitrophic Level Interactions. Cambridge University Press, Cambridge, pp. 44-65.

Chau A., Heinz K.M. \& Davies F.T. 2005: Influences of fertilization on population abundance, distribution, and control of Frankliniella occidentalis on chrysanthemum. - Entomol. Exp. Appl. 117: 27-39.

CoOper L.B., Murphy J.F. \& Eubanks M.D. 2007: Red imported fire ants (Hymenoptera: Formicidae) increase the abundance of aphids in tomato. - Fla Entomol. 3: 419-425.

Cushman J.H., Rashbrook V.K. \& Beattie A.J. 1994: Assessing benefits to both participants in a lycaenid-ant association. Ecology 75: 1031-1041

Dauber J., Schroeter D. \& Wolters V. 2001: Species specific effects of ants on microbial activity and $\mathrm{N}$-availability in the soil of an old-field. - Eur. J. Soil Biol. 37: 259-261.

DAuber J. \& Wolters V. 2000: Microbial activity and functional diversity in the mounds of three different ant species. - Soil Biol. Biochem. 32: 93-99.

DeAn W.R.J. \& Yeaton R.I. 1993: The inluence of harvester ant Messor capensis nest-mounds on the productivity and distribution of some plant species in the southern Karoo, South Africa. - Vegetatio 106: 21-35.

Dean W.R.J., Milton S.J. \& Klotz B. 1997: The role of ant nestmounds in maintaining small-scale patchiness in dry grasslands in central Germany. - Biodivers. Conserv. 6: 1293-1307.

EL-Ziady S. 1960: Further effects of Lasius niger L. on Aphis fabae Scopoli. - Proc. R. Soc. Lond. (B) 35: 30-38.

El-Ziady S. \& KenNEdy J.S. 1956: Beneficial effects of the common garden ant, Lasius niger L., on the black bean aphid, Aphis fabae Scopoli. - Proc. R. Soc. Lond. (B) 31: 61-65.

Fischer M.K., VölKL W., Schopf R. \& Hoffmann K.H. 2002: Age-specific patterns in honeydew production and honeydew composition in the aphid Metopeurum fuscoviride: implications for ant-attendance. - J. Insect Physiol. 48: 319-326.
Fischer M.K., VölKL W. \& HoffmanN K.H. 2005: Honeydew production and honeydew sugar composition of polyphagous black bean aphid, Aphis fabae (Hemiptera: Aphididae) on various host plants and implications for ant-attendance. - Eur. J. Entomol. 102: 155-160.

FlatT T. \& Weisser W.W. 2000: The effects of mutualistic ants on aphid life history traits. - Ecology 81: 3522-3529.

Hansen S., Hattendorf J. \& Nentwig W. 2006: Mutualistic relationship beneficial for aphids and ants on giant hogweed (Heracleum mantegazzianum). - Commun. Ecol. 7: 43-52.

Hosseini M., Ashouri A., Enkegaard A., Goldansaz S.H., Nasiri Mahalati M. \& Hosseininaveh V. 2010: Performance and population growth rate of the cotton aphid and associated yield losses of cucumber under different nitrogen fertilization regimes. - Int. J. Pest Manag. 56: 127-137.

Hosseini A., Modarres Awal M. \& Hosseini M. 2015: New faunistic records of Formicidae (Insecta: Hymenoptera) from Iran's Northeast. - Asian Myrmecol. 7: 113-127.

Howell D.C. 2002: Statistical Methods for Psychology. Duxbury Press, Belmont, CA, $802 \mathrm{pp}$

Katayama N., Silva A.O., Kishida O., Ushio M., Kita S. \& OhGUSHI T. 2014: Herbivorous insect decreases plant nutrient uptake: the role of soil nutrient availability and association of below-ground symbionts. - Ecol. Entomol. 39: 511-518.

Morales M.A. 2000: Mechanisms and density dependence of benefit in an antmembracid mutualism. - Ecology 81: 482489.

Pierce N.E., Kitching R.L., Buckley R.C., Taylor M.F.J. \& BenBOw K.F. 1987: The costs and benefits of cooperation between the Australian lycaenid butterfly, Jalmenus evagoras, and its attendant ants. - Behav. Ecol. Sociobiol. 21: 237-248.

PonTIN A.J. 1958: A preliminary note on the eating of aphids by ants of the genus Lasius (Hym., Formicidae). - Entomol. Month. Mag. 94: 9-11.

Powell B.E. \& Silverman J. 2010: Population growth of Aphis gossypii and Myzus persicae (Hemiptera: Aphididae) in the presence of Linepithema humile and Tapinoma sessile (Hymenoptera: Formicidae). — Environ. Entomol. 39: 1492-1499.

Prado E. \& TuallingiI W.F. 1997: Effects of previous plant infestation on sieve element acceptance by two aphids. - Entomol. Exp. Appl. 82: 189-200.

Price P.W., Denno R.F., Eubanks M.D., Finke D.L. \& Kaplan I. 2011: Insect Ecology: Behavior, Populations and Communities. Cambridge University Press, Cambridge, 816 pp.

Renault C.K., Buffa L.M. \& Delfino M.A. 2005: An aphid-ant interaction: effects on different trophic levels. - Ecol. Res. 20: $71-74$.

SAS Institute 2008: Release 9.2. SAS Institute, Cary, NC.

SAKATA H. 1995: Density-dependent predation of the ant Lasius niger (Hymenoptera: Formicidae) on two attended aphids Lachnus tropicalis and Myzocallis kuricola (Homoptera: Aphididae). - Res. Popul. Ecol. 37: 159-164.

SCHEINER S.M. 2001: MANOVA: Multiple response variables and multispecies interactions. In Scheiner S.M. \& Gurevitch J. (eds): Design and Analysis of Ecological Experiments. Oxford University Press, Oxford, UK, pp. 99-115.

Singh A., Zytynska S.E., Hanna R. \& Weisser W.W. 2016: Ant attendance of the cotton aphid is beneficial for okra plants: deciphering multitrophic interactions. - Agr. Forest Entomol.18: 270-279.

Stadler B. \& Dixon A.F.G. 1998: Costs of ant-attendance for aphids. - J. Anim. Ecol. 67: 454-459.

StAdLeR B. \& Dixon A.F.G. 1999: Ant attendance in aphids: why different degrees of myrmecophily? - Ecol. Entomol. 24: 363-369. 
Stadler B. \& Dixon A.F.G. 2005: Ecology and evolution of aphid-ant interactions. - Annu. Rev. Ecol. Evol. Syst. 36 345-372.

StYrSKY J.D. \& EubANKS M.D. 2010: A facultative mutualism between aphids and an invasive ant increases plant reproduction. - Ecol. Entomol. 35: 190-199.

ToKunAga E. \& SuzuKi N. 2008: Colony growth and dispersal in the ant-tended aphid, Aphis craccivora Koch, and the non-anttended aphid, Acyrthosiphon pisum Harris, under the absence of predators and ants. - Popul. Ecol. 50: 45-52.

van Emden H.F. \& Harrington R. 2007: Aphids as Crop Pests. CABI, Wallingford, $717 \mathrm{pp}$.

Vehrs S.L.C., Walker G.P. \& Parrella M.P. 1992: Comparison of population growth rate and within-plant distribution between Aphis gossypii and Myzus persicae (Homoptera: Aphididae) reared on potted chrysanthemums. - J. Econ. Entomol. 85: 799-807.
WAY M.J. 1954: Studies on the association of the ant Oecophylla longinoda (Latr.) (Formicidae) with the scale insect Saissetia zanzibarensis Williams (Coccidae). — Bull. Entomol. Res. 45: 113-134.

YAO I. 2014: Costs and constraints in aphid-ant mutualism. Ecol. Res. 29: 383-391.

Yао I., Sнiвао H. \& Акімото S. 2000: Costs and benefits of ant attendance to the drepanosiphid aphid Tuberculatus quercicola. - Oikos 89: 3-10.

Yoo H.J.S. \& Holway D.A. 2011: Context-dependence in an antaphid mutualism: direct effects of tending intensity on aphid performance. - Ecol. Entomol. 36: 450-458.

ZHANG S., Zhang Y. \& MA K. 2015: Mutualism with aphids affects the trophic position, abundance of ants and herbivory along an elevational gradient. - Ecosphere 6(12): 253, 11 pp.

Received November 11, 2016; revised and accepted January 16, 2017 Published online February 9, 2017 